\title{
THE SHORT-TERM RELATIONSHIPS AMONG THE U.S., GERMAN AND GREEK BOND MARKETS IN TIMES OF FINANCIAL CRISES. A BAYESIAN ANALYSIS OF EXOGENEITY IN THE VAR-SV MODEL
}

This paper examines short-run relationships among the U.S., German and Greek bond markets in times of financial crises. Specifically, the connections among daily and weekly growth rates of the 10-year government bond yields of the U.S., Germany and Greece from July 13, 2006 to January 29, 2016 are considered and an empirical illustration of those, based on the vector autoregressive (VAR) model with stochastic volatility (SV) disturbances, is provided. Finally, sufficient weak and strong exogeneity conditions in the VAR-SV models are tested.

Our results indicate that during the time period covered by the analysis, the weekly growth rates of the 10-year U.S. bond yields were not affected by the past growth rates of the 10 -year German and Greek bond yields. Contagion effects were absent among all the 10-year bond markets considered. From October 2008 to April 2015 a 'flight to quality' effect between Germany and Greece, as well as between the U.S. and Greece seems to have occurred.

Since the strong exogeneity hypothesis of the 10-year US bond yields' weekly growth rates has not been rejected by the data, they can be predicted from the marginal model only, i.e. without taking the German and Greek bond yields into consideration.

Keywords: international bond markets, financial crisis, exogeneity, stochastic volatility

JEL classification: $\mathrm{G} 15, \mathrm{G} 01, \mathrm{C} 11, \mathrm{C} 32$

DOI: $10.15611 /$ aoe.2017.1.10

\section{INTRODUCTION}

The financial crisis that originated from the crash of the U.S. housing market in mid-2007 followed by the Lehman Brothers bankruptcy in 2008, has reversed the convergence trend in the Eurozone government bond market, which was clearly recognizable after the introduction of the common currency in 1999. The onset of the sovereign debt crisis in Europe at the end of 2009, closely related to the worsening economic situation in Greece, has reinforced the tendency towards a cross-country bond yields differentiation leading to a greater market fragmentation. As a result, European government

\footnotetext{
* Cracow University of Economics, Faculty of Economics and International Relations, Department of Foreign Trade, Cracow

** Cracow University of Economics, Faculty of Finance and Law, Department of Mathematics, Cracow
} 
bond spreads remained at higher levels in 2012 in comparison to the precrisis years resembling those of the pre-Euro introduction period.

One of the reasons for the differentiated pricing of sovereign debt securities across European countries was the stronger impact of domestic factors highly neglected by the bond market participants in 1999-2007. The influence of country-specific factors such as national fiscal conditions and macroeconomic imbalances (credit risk) together with market liquidity (liquidity risk) on government bond yields, was confirmed by Barrios et al. (2009). Nevertheless, a major role in explaining the differentials of Euro area sovereign bond yields was played by international factors, especially investors' risk aversion (Barrios et al., 2009). In times of financial instability, investors typically engage in a 'flight to quality' (and a 'flight to liquidity, ${ }^{1}$, i.e. they substitute safe assets for more risky ones. Since government bonds are perceived as 'safe havens', investors substitute bonds for stocks, and as a consequence, bond and stock market returns have become negatively correlated (Kim et al., 2006). Similarly, as in terms of credit quality and liquidity, German Bunds have been considered the 'safest haven' among European sovereign bonds (Barrios et al., 2009) and the Greek ones the least safe, yields on both should be negatively correlated during a financial crisis.

However, the developments in the Euro area government bond markets cannot merely be assessed from the regional perspective. Discernible crossborder co-movements of bond yields signal the presence of common driving factors at global level as well. In particular, there is much empirical evidence supporting a substantial interdependence between the U.S. and European sovereign bond markets (Goldberg and Leonard, 2003; Engsted and Tanggaard, 2007, Laopodis, 2008; Andersson et al., 2009; Georgoutsos and Migiakis 2012). In times of financial stability, government bond yields in these markets tend to move together displaying a high degree of positive correlation. This holds true especially for the U.S. Treasuries and the German Bunds (Goldberg and Leonard, 2003; Engsted and Tanggaard, 2007, Georgoutsos and Migiakis, 2012), which in the global sovereign debt market are deemed to be benchmark securities (U.S. Treasuries serve as international benchmarks, and German Bunds - as regional ones). Considering the facts that the 2007-2008 financial crisis began in the U.S. and the U.S. Treasuries as global benchmark securities assign prices to other assets, the question arises whether, and if so, to what extent the changes in Euro area government bond yields were affected by the changes in yields of the U.S. Treasuries.

\footnotetext{
${ }^{1}$ Risky assets are usually less liquid.
} 
On the other hand, the downgrading of the Greek public debt to junk level (BBB-) by rating agency Fitch in April 2010 threatened the stability of the whole Euro area, bringing the bond yields of larger European economies under pressure in 2011 (IMF, 2012). On November 23, 2011, Germany, considered a stalwart pillar of the Eurozone economy, failed to get bids for $35 \%$ of the 10-year government bonds offered for auction sale, which made it clear that even German Bunds are not immune to the ongoing sovereign debt crisis in Europe $^{2}$. As the German bond market seems to have been affected by the dysfunction of the Greek bond market since the end of April 2010, another question addressed in this paper is about the potential impact of the European bond markets on that of the U.S. during financial turmoil. It is worth noting that earlier in the same year, on August 5, 2011, Standard \& Poor's downgraded the U.S. sovereign debt from AAA to AA+, which increased speculation about the potential loss of the benchmark status of the U.S. Treasuries (IMF, 2012). Hence, an analysis of the connections between the U.S. and German government bonds, acting as close substitutes in the global bond market, seems to be especially interesting.

Thus the aim of this paper is to study short-term relationships among selected government bond markets, namely that of the U.S. (the global benchmark), Germany (the regional benchmark) and Greece (the country most severely affected by the sovereign-debt crisis) in the presence of high levels of market uncertainty. In particular, the strength and direction (the sign) of bilateral linkages among yields in the sovereign debt markets of those countries will be examined, i.e. we are going to check how the past changes in 10 -year government bond yields in one country have determined the present changes in 10-year government bond yields in another country. Additionally, the contagion effect between all pairs of sovereign government bonds considered will be studied. Last but not least, the sufficient weak and strong exogeneity conditions are going to be tested in the vector autoregressive (VAR) model whose disturbances follow the stochastic volatility (SV) process. The Bayesian concept of exogeneity adopted in this paper was proposed by Florens and Mouchart (Florens and Mouchart, 1982, 1985; Florens et al., 1990; Osiewalski and Steel, 1996), and then extended by Pajor (2011), to the class of models with latent variables (in which a subset of parameters and latent variables is of interest). By combining the VAR and SV structures into a VAR-SV model, typical features of data considered that are known as stylized facts (see e.g. Campbell et al., 1997), can be taken into

\footnotetext{
2 www.bloomberg.com/news/2011-11-23/germany-fails-to-receive-bids-for-35-of-10-yearbunds-offered-at-auction.html (accessed 23 Nov. 2011).
} 
account. In turn, due to the presence of latent variables in the SV structure the Bayesian approach becomes a natural framework for statistical inference.

The investigation of reciprocal relationships among the selected sovereign bond markets seems to be of importance for several reasons: firstly, the US as the world's leading economy is its largest debtor at the same time, secondly, Germany as the EU's leading economy is the EU's largest creditor having the greatest impact on the Euro area currency ${ }^{3}$, and thirdly, Greece, as one of the EU's largest debtors, became on June 30, 2015 the first developed country that failed to make an IMF loan repayment ${ }^{4}$.

The remainder of this paper is organized as follows: Section 2 briefly reviews the empirical studies which fit the line of our research, Section 3 introduces the Bayesian econometric VAR-SV model together with the formal definition of exogeneity, Section 4 discusses the dataset and empirical results, and finally Section 5 concludes by providing the key findings.

\section{LITERATURE REVIEW}

The sovereign debt crisis in Europe shifted interest to government bond markets again, thus raising the problem of their international interdependence in the context of the transmission of financial shocks. Previous analyses of interactions among the European sovereign bond markets have seldom been carried out in isolation from the global market. For instance, Sosvilla-Rivero and Morales-Zumaquero (2012), studied the volatility of the daily 10-year sovereign bond yields for 11 EMU countries during the decade 2001-2010, using a C-GARCH model and cluster analysis. Their results suggest that for all the countries and time periods, the transitory (short-term) component of bond-yield volatility was less important than the permanent (long-term) one. In other words, shocks to underlying economic fundamentals had a greater impact on the volatility of government bond yields than temporary shifts in the bond markets. Moreover, the correlation analyses and Granger causality tests between transitory and permanent volatilities of sovereign bond yields confirmed the existence of two groups of EMU countries, characterized by a different degree of credibility ascribed to the announcements made by policymakers and by various positions regarding the stability of public finance. It came as no surprise that Germany

\footnotetext{
${ }^{3}$ http://documents.worldbank.org/curated/en/597691468150580088/pdf/626980PUB0Mult000 public00BOX361489B.pdf (accessed 28 Apr. 2017).

4 www.bbc.com/news/world-europe-33325886?ocid=global_bbccom_email_30062015_top+ new+news+stories (accessed $30 \mathrm{Ju}$. 2015).
} 
and Greece belonged to the distinct groups, i.e. to the EMU-core and periphery respectively, which means that there was a rather weak relation between the volatilities of their bond yields in the period 2001-2010.

Nevertheless the empirical study of Sosvilla-Rivero and MoralesZumaquero (2012) did not cover the actual period of sovereign debt crisis in Europe, and in times of financial instability, markets behave differently. They are more volatile and become more highly correlated (Chordia et al., 2001). Therefore during periods of financial stress the external factor plays a more important role than the domestic one (Clare and Lekkos, 2000). Claeys and Vašiček (2014), who measured the bilateral spillovers between $16 \mathrm{EU}$ government bond markets from May 2000 up to February 2012, using the forecast-error variance decomposition of a VAR model on sovereign bond yield spreads relative to the German 10-year bond yield, indicated that 59\% of the variations in sovereign bond spreads could be explained by shocks to other European countries, i.e. the regional factor, and only the remaining $41 \%$ of all movements were determined by a purely domestic factor. The authors also suggest that spillover has substantially increased since 2007, and it was of greater significance than domestic factors to all EMU countries due to the influence of the common factor as well as bilateral linkages. In the case of Greece, however, domestic dynamics were slightly more important than the international ones.

Furthermore, Claeys and Vašiček (2014) examined the spillover of fiscal problems in Greece to other European bond markets. They observed that the influence of changes in Greek sovereign bond spreads on other markets was varying significantly over time, and it was quite different across four identified groups of countries. The most affected were the bond markets of Ireland, Italy, Portugal and Spain (IIPS) and those of the core EMU countries (Austria, Belgium, France, Finland and the Netherlands), whereas the bond markets of the CEE (the Czech Republic, Hungary and Poland) and those of the non-EMU countries (Denmark, Sweden and the UK) remained barely influenced. However, since May 2010 the spillover to the European bond markets has been rather reduced. The time-varying effect of shocks was also measured in the opposite direction, i.e. the influence of other European bond markets on the Greek one was calculated. The overall effect was stable, and again there were stronger links between the core EMU, the IIPS countries, and Greece.

As mentioned in the previous paragraph, analyses of interactions among European bond markets have usually been conducted within the global context, i.e. next to the influence of the domestic and regional factor, the 
global factor has been also taken into consideration. Such an approach was adopted by Christiansen (2003), who studied volatility spillovers from the US and aggregate European bond markets into six EMU (Belgium, France, Germany, Italy, the Netherlands and Spain) and three non-EMU countries (Denmark, Sweden and the UK), using a GARCH volatility-spillover model with the weekly data of total return government bond indices for the time period from January 6, 1988 to November 27, 2002. Three volatility effects were measured: global, regional and local. The regional effect followed by the local one appeared to be the most important for the EMU countries and Denmark. Additionally, the introduction of a common currency has strengthened the European and weakened the US volatility-spillover effect for the EMU bond markets. In the case of non-EMU countries the local and global effects were of greater importance than the regional one which turned out to be rather weak.

Da Costa et al. (2004), who followed the research method applied by Christiansen, examined the volatility-spillover effects from the U.S. and Germany to EMU countries with the weekly data of return indices for 7 and 10-year government bond markets from October 1993 to May 2004. They proved, however, that most European bond markets were strongly affected by volatility-spillover effects, coming both from the global (the U.S.) and regional (German) markets. Moreover, the spillover effects have increased significantly after the introduction of the common currency, whereas the local effect has declined in importance after 1999.

On the other hand, the findings of Abad et al. (2010) are consistent with the results of Christiansen, although a different research method was used. Abad et al. (2010) adopted Bekaert and Harvey's CAPM-based model (1995), to analyse the behaviour of 10-year sovereign bond returns of 13 European countries (Greece and Luxembourg were not included in the sample) with a weekly dataset covering the period from January 1999 to June 2008. The adoption of this model also allowed them to separate each individual country's government bond return into three effects: local (own country), regional (Eurozone) and global (the U.S.). Significant distinctions between EMU and non-EMU countries were recognized. The degree of integration with the US and German bond markets varied clearly between these two groups of countries. The authors indicated that the EMU countries sharing a single monetary policy were more vulnerable to the influence of regional risk factors and less vulnerable to the global risk factors. Their results suggest that the EMU bond markets were only partially integrated with the German market because of differences in their 
market liquidity or default risk. In contrast, the non-EMU countries presented higher vulnerability to external risk factors i.e. their bond markets were more affected by the U.S. market.

Another line of empirical research on the interactions of European government bond markets places a special emphasis on the relationship between the U.S. and Germany. The interdependence between these two markets has been usually investigated in the context of the high level of their co-movements. Goldberg and Leonard (2003) used 30 months of hourly yield data for the on-the-run U.S. and German 2- and 10-year notes from January 3, 2000, to June 28, 2002. The U.S. economic news was found to have had a direct and strong influence on German yields within an hour of its release. The effect in the opposite direction, however, appeared to be far less influential. According to Engsted and Tanggaard (2007), who used a VAR model for monthly data over the period of 1975-2003 to decompose the U.S. and German unexpected bond returns into three news components, news about: future inflation, future real interest rates and future excess bond returns, the main driving force behind the co-movement of the U.S. and German bond markets was inflation news coming from the U.S. Furthermore they proved that there were important spillover effects from the U.S. to the German bond market but only limited ones from Germany to the U.S., and that these two markets were closely linked together since one-month excess bond returns in the U.S. and Germany showed a contemporaneous positive correlation of 0.54 . The significant impact of the U.S. announcements on German government bond returns was also confirmed by Andersson et al. (2009), who examined the effects of macroeconomic data releases and the ECB's monetary policy statements on the German long-term bond market segment of the yield curve in the period from January 1999 to December 2005. Their results suggest that the U.S. macroeconomic releases exert a stronger influence on the German bond markets than the Euro area and domestic news, and the strength of those reactions has increased over the period considered.

Interactions among international government bond markets have also been studied across various classes of financial assets (currencies, stocks, and bonds etc.). Despite the fact that this kind of approach, similarly to the previous paragraph, goes beyond the scope of this research, it is worth noting that in times of financial crises shocks emanating from the U.S. asset markets are transmitted worldwide and in a negative direction within-market (as in the case of equity and bond markets) as well as cross-market from the U.S. equity 
to bond market, whereas the Euro area shocks mainly have a negative effect on the bond markets and are largely confined to spillovers to the bond markets of advanced economies. Beirne and Gieck (2014) have come to such conclusions while investigating over 60 economies in the periods of financial stress between 1998 and 2011 with the use of a GVAR model. The dominance of the U.S. as the main driver of global financial markets was also proved by Ehrmann et al. (2011). They applied a multifactor model to analyse daily returns of a 16-year period of 1998-2004 for seven asset prices: short-term interest rates, bond yields, equity market returns and the exchange rate in the U.S. and the Euro area. Their results suggest that the U.S. financial markets were the explanation for, on average, more than $25 \%$ of the movements in the Eurozone financial markets, while the Euro area markets were responsible for only $8 \%$ of the U.S. price changes. The international transmission of shocks was strengthened in times of recession.

The investigations hitherto conducted on interactions among international bond markets allow us to assume a stronger relationship between the U.S. and Germany and between Germany and Greece than between the U.S. and Greece. The direction (the sign) of bilateral linkages between each pair of these countries will determine whether the crisis stimulated a 'flight to quality' phenomenon.

This paper contributes to the existing literature in a number of ways. Firstly, it examines the connections among the selected government bond markets in times of financial crises. Secondly, it employs the VAR-SV model to investigate the exogeneity of the U.S. Treasury bonds in relation to the sovereign bonds of Germany and Greece. Thirdly, it uses the Bayesian framework to analyse these linkages, and to our knowledge, none of the researchers has so far investigated the relationships of these bond markets with the use of the Bayesian VAR-SV model.

\section{METHODOLOGICAL FRAMEWORK}

\subsection{Bayesian econometric VAR-SV model}

Let $x_{t, j}$ denote the 10-year bond yields of country $j$ at time $t$ for $j=1,2,3$ and $t=1,2, \ldots, T$. The vector of growth rates $\mathbf{Y}_{t}=\left(y_{t, 1}, y_{t, 2}, y_{t, 3}\right)^{\prime}$, each defined by the formula $y_{t, j}=100 \ln \left(x_{t, j} / x_{t-1, j}\right)$, is modelled using the basic $\operatorname{VAR}(1)$ framework:

$$
\mathbf{Y}_{t}-\mathbf{B}=\mathbf{R}\left(\mathbf{Y}_{t-1}-\mathbf{B}\right)+\Xi_{t}
$$


where $\mathbf{R}$ is a $3 \times 3$ matrix of the autoregressive coefficients, $\mathbf{B}$ is a $3 \times 1$ mean vector, $\left\{\Xi_{t}\right\}$ is a trivariate SV process. More specifically:

$$
\begin{gathered}
{\left[\begin{array}{l}
y_{t, 1} \\
y_{t, 2} \\
y_{t, 3}
\end{array}\right]-\left[\begin{array}{l}
b_{1} \\
b_{2} \\
b_{3}
\end{array}\right]=} \\
=\left[\begin{array}{lll}
r_{11} & r_{12} & r_{13} \\
r_{21} & r_{22} & r_{23} \\
r_{31} & r_{32} & r_{33}
\end{array}\right]\left(\left[\begin{array}{l}
y_{t-1,1} \\
y_{t-1,2} \\
y_{t-1,3}
\end{array}\right]-\left[\begin{array}{l}
b_{1} \\
b_{2} \\
b_{3}
\end{array}\right]\right)+\left[\begin{array}{l}
\xi_{t, 1} \\
\xi_{t, 2} \\
\xi_{t, 3}
\end{array}\right], t=1, \ldots, T .
\end{gathered}
$$

Vector autoregressive structures play an essential role in economic time series analyses (see e.g. Lütkepohl, 2005). In VAR(1) model each component of the vector $\mathbf{Y}_{t}$ depends linearly on its own nearest past value as well as on the nearest past values of all other variables. Moreover, all included variables are assumed to be endogenous (the VAR model can be treated as a reduced form of the econometric model). Thus, with such a model we can test conditions for exogeneity.

We assume that conditionally on the latent variable vector, $\left(\mathbf{Q}_{t}\right.$, introduced later) $\Xi_{t}$ follows a trivariate Gaussian distribution with mean vector $\mathbf{0}_{[3 \times 1]}$ and covariance matrix $\boldsymbol{\Sigma}_{t}$, i.e. $\boldsymbol{\Xi}_{t} \mid \mathbf{Q}_{t} \sim N\left(\mathbf{0}_{[3 \times 1]}, \boldsymbol{\Sigma}_{t}\right)$, $t=1,2, \ldots, T$. We employ the specification of the conditional covariance matrix as in Tsay (2002). Thus the Cholesky decomposition is used:

$$
\Sigma_{t}=\mathbf{L}_{t} \mathbf{G}_{t} \mathbf{L}_{t}^{\prime},
$$

where $\mathbf{L}_{t}$ is a lower triangular matrix with unitary diagonal elements, and $\mathbf{G}_{t}$ is a diagonal matrix with positive diagonal elements:

$$
\mathbf{L}_{t}=\left[\begin{array}{ccc}
1 & 0 & 0 \\
q_{t, 21} & 1 & 0 \\
q_{t, 31} & q_{t, 32} & 1
\end{array}\right], \mathbf{G}_{t}=\left[\begin{array}{ccc}
q_{t, 11} & 0 & 0 \\
0 & q_{t, 22} & 0 \\
0 & 0 & q_{t, 33}
\end{array}\right] ;
$$

$\left\{q_{t, i j}\right\}$, and $\left\{\ln q_{t, j j}\right\}(i, j=1,2,3, i>j)$, as in the univariate $\mathrm{SV}$, are standard univariate autoregressive processes of order one, namely:

$$
\begin{gathered}
\ln q_{t, j j}-\gamma_{j j}=\varphi_{i j}\left(\ln q_{t-1, j j}-\gamma_{j j}\right)+\sigma_{j j} \eta_{t, j j}, j=1,2,3, \\
q_{t, i j}-\gamma_{i j}=\phi_{i j}\left(q_{t-1, i j}-\gamma_{i j}\right)+\sigma_{i j} \eta_{t, i j}, j, i \in\{1,2,3\}, i>j,
\end{gathered}
$$




$$
\begin{gathered}
\mathbf{H}_{t}=\left(\eta_{t, 11} \eta_{t, 22}, \eta_{t, 33}, \eta_{t, 21}, \eta_{t, 31}, \eta_{t, 32}\right)^{\prime}, \\
\left\{\mathbf{H}_{t}\right\} \sim i i N_{6}\left(\mathbf{0}_{[6 \times 1]}, \mathbf{I}_{6}\right), t \in\{1, \ldots, T\}, \\
\mathbf{Q}_{t}=\left(q_{t, 11}, q_{t, 22}, q_{t, 33}, q_{t, 21}, q_{t, 31}, q_{t, 32}\right)^{\prime} .
\end{gathered}
$$

It can easily be shown that if the absolute values of $\phi_{i j}$ are less than one, the SV process is a vector white noise (see Pajor, 2005). The conditional distribution of $\mathbf{Y}_{t}$ (given the past of the process $\Psi_{t-1}$, the parameters and the latent variable vector, $\left.\mathbf{Q}_{t}\right)$ is a trivariate Normal with mean vector $\mathbf{M}_{t}=\mathbf{B}+\mathbf{R}\left(\mathbf{Y}_{t-1}-\mathbf{B}\right)$ and covariance matrix $\boldsymbol{\Sigma}_{\mathrm{t}}$ :

$$
\left(y_{t, 1}, y_{t, 2}, y_{t, 3}\right)^{\prime} \mid \mathbf{B}, \mathbf{R}, \mathbf{Q}_{t}, \Psi_{t-1} \sim N_{3}\left(\mathbf{M}_{t}, \mathbf{\Sigma}_{t}\right) .
$$

To obtain the Bayesian model we need to specify a prior distribution of the parameters. For all elements of $\mathbf{B}$ and $\mathbf{R}$ we assume the multivariate standard Normal prior, $N_{12}(\mathbf{0}, \mathbf{I})$. For the remaining parameters we assume the following prior distributions (see Pajor, 2011): $\left(\gamma_{i j}, \phi_{i j}\right)^{\prime} \sim N_{2}\left(0,10^{2} \mathbf{I}\right)$ $I_{(-1,1)}\left(\phi_{i j}\right), \sigma_{i j}^{-2} \sim G(1,0.005), \ln q_{i i, 0} \sim N_{1}\left(0,10^{2}\right)$ for $i, j \in\{1,2,3\}$ and $i \geq j$; $q_{i j, 0} \sim N_{1}\left(0,10^{2}\right)$ for $i, j \in\{1,2,3\}, i>j$, where $N_{n}(\mathbf{M}, \mathbf{S})$ denotes the $n$-variate Normal distribution with mean vector $\mathbf{M}$ and covariance matrix $\mathbf{S}$, $G(a, b)$ denotes the Gamma distribution with shape parameter $a$ and precision parameter $b$, the mean being $a / b$, and $\mathrm{I}_{(-1,1)}(\cdot)$ is the indicator function of the interval $(-1,1)$. The prior distributions used are relatively non-informative.

\subsection{Exogeneity in the VAR-SV model}

To formally test the sufficient conditions for the strong exogeneity of the growth rates of 10-year U.S. bond yields we use the Lindley type test in the VAR-SV model for selected countries: the U.S., Germany and Greece. Following Pajor (2011), we partition $\mathbf{Y}_{t}$ and $\boldsymbol{\Sigma}_{\mathrm{t}}$, conformably, into:

$$
\mathbf{Y}_{t}=\left[\begin{array}{c}
z_{t} \\
\mathbf{W}_{t}
\end{array}\right] \text { and } \boldsymbol{\Sigma}_{t}=\left[\begin{array}{cc}
\Sigma_{t, 11} & \boldsymbol{\Sigma}_{t, 12} \\
\boldsymbol{\Sigma}_{t, 21} & \boldsymbol{\Sigma}_{t, 22}
\end{array}\right] \text {, }
$$

where $z_{t}$ is a scalar: $z_{t}=y_{t, 1}$, and $\mathbf{W}_{t}$ has two elements: $\mathbf{W}_{t}=\left(y_{t, 2}, y_{t, 3}\right)^{\prime}$. After partitioning, equation (2) becomes:

$$
\left[\begin{array}{c}
z_{t} \\
\mathbf{W}_{t}
\end{array}\right]=\left[\begin{array}{c}
b_{1} \\
\mathbf{B}_{-1}
\end{array}\right]+\left[\begin{array}{ll}
R_{11} & \mathbf{R}_{12} \\
\mathbf{R}_{21} & \mathbf{R}_{22}
\end{array}\right]\left(\left[\begin{array}{c}
z_{t-1} \\
\mathbf{W}_{t-1}
\end{array}\right]-\left[\begin{array}{c}
b_{1} \\
\mathbf{B}_{-1}
\end{array}\right]\right)+\left[\begin{array}{c}
\varepsilon_{t, 1} \\
\mathbf{E}_{t, 2}
\end{array}\right],
$$


where $\mathbf{B}_{-1}=\left(b_{2}, b_{3}\right)^{\prime}, \mathbf{E}_{2, t}=\left(\xi_{t, 2}, \xi_{t, 3}\right)^{\prime}, R_{11}=r_{11}, \mathbf{R}_{12}=\left(r_{12}, r_{13}\right), \mathbf{R}_{21}=$ $\left(r_{21}, r_{31}\right)^{\prime}$,

$$
\mathbf{R}_{22}=\left[\begin{array}{ll}
r_{22} & r_{23} \\
r_{32} & r_{33}
\end{array}\right] .
$$

The VAR form in (6) can be reparameterized as follows:

$$
\begin{aligned}
& z_{t}-b_{1}=R_{11}\left(z_{t-1}-b_{1}\right)+\mathbf{R}_{12}\left(\mathbf{W}_{t-1}-\mathbf{B}_{-1}\right)+\varepsilon_{t, 1} \\
& \mathbf{W}_{t}-\mathbf{B}_{-1}=\left(\mathbf{R}_{22}-\mathbf{D}_{t} \mathbf{R}_{12}\right)\left(\mathbf{W}_{t-1}-\mathbf{B}_{-1}\right)+\left(\mathbf{R}_{21}-\mathbf{D}_{t} R_{11}\right)\left(z_{t-1}-b_{1}\right)+ \\
& +\mathbf{D}_{t}\left(z_{t}-b_{1}\right)+\left(\mathbf{E}_{2, t}-\mathbf{D}_{t} \varepsilon_{t, 1}\right),
\end{aligned}
$$

where

$$
\begin{gathered}
{\left[\begin{array}{c}
\varepsilon_{t, 1} \\
\boldsymbol{\varepsilon}_{t, 2}-\mathbf{D}_{t} \varepsilon_{t, 1}
\end{array}\right] \mid \mathbf{Q}_{t} \sim N_{3}\left(\mathbf{0},\left[\begin{array}{cc}
\Sigma_{t, 11} & \mathbf{0} \\
\mathbf{0} & \boldsymbol{\Sigma}_{t, 22.1}
\end{array}\right]\right), \quad \boldsymbol{\Sigma}_{t, 22.1}=\boldsymbol{\Sigma}_{t, 22}-\boldsymbol{\Sigma}_{t, 21} \Sigma_{t, 11}^{-1} \boldsymbol{\Sigma}_{t, 12},} \\
\mathbf{D}_{t}=\boldsymbol{\Sigma}_{t, 21} \Sigma_{t, 11}^{-1}=\left[\begin{array}{c}
q_{t, 21} \\
q_{t, 31}
\end{array}\right], \quad \Sigma_{11, t}=\left[q_{t, 11}\right], \quad \boldsymbol{\Sigma}_{t, 22.1}=\left[\begin{array}{cc}
q_{t, 22} & q_{t, 22} q_{t, 32} \\
q_{t, 22} q_{t, 32} & q_{t, 33}+q_{t, 22} q_{t, 32}^{2}
\end{array}\right] .
\end{gathered}
$$

The latent variables and parameters of the conditional model (7) are

$$
\begin{aligned}
\left(\operatorname{vec}\left(\tilde{\mathbf{Q}}_{T}^{1, w}\right)^{\prime}, \boldsymbol{\Theta}_{1}{ }^{\prime}\right)^{\prime}= & \left(\left(\mathbf{R}_{21}-\mathbf{D}_{1} R_{11}\right)^{\prime}, \ldots,\left(\mathbf{R}_{21}-\mathbf{D}_{T} R_{11}\right)^{\prime},\right. \\
& \operatorname{vec}\left(\mathbf{R}_{22}-\mathbf{D}_{1} \mathbf{R}_{12}\right)^{\prime}, \ldots, \operatorname{vec}\left(\mathbf{R}_{22}-\mathbf{D}_{T} \mathbf{R}_{12}\right)^{\prime}, \\
& \left.\mathbf{D}_{1}{ }^{\prime}, \ldots, \mathbf{D}_{T}{ }^{\prime}, \operatorname{vec}\left(\boldsymbol{\Sigma}_{1,22.1}\right)^{\prime}, \ldots, \operatorname{vec}\left(\mathbf{\Sigma}_{T, 22.1}\right)^{\prime}, b_{1}, \mathbf{B}_{-1}{ }^{\prime}, \boldsymbol{\Theta}_{1}^{q, w}\right)^{\prime},
\end{aligned}
$$

and those of the marginal model (6) are

$$
\left(\operatorname{vec}\left(\tilde{\mathbf{Q}}_{T}^{1, z}\right)^{\prime}, \boldsymbol{\Theta}_{2}{ }^{\prime}\right)^{\prime}=\left(\Sigma_{1,11}, \ldots, \Sigma_{T, 11}, b_{1}, \mathbf{B}_{-1}{ }^{\prime}, R_{11}, \mathbf{R}_{12}, \boldsymbol{\Theta}_{2}^{q, z}\right)^{\prime},
$$

where $\boldsymbol{\Theta}_{1}^{q, w}$ and $\boldsymbol{\Theta}_{2}^{q, z}$ are vectors of parameters in the equations for $\mathbf{Q}_{t}^{w}=\left(q_{t, 21}, q_{t, 31}, q_{t, 22}, q_{t, 32}, q_{t, 33}\right)^{\prime}, \quad$ and $\quad Q_{t}^{z}=q_{t, 11}, \quad$ respectively, $\mathbf{Q}_{t}^{1, w}=\left[\mathbf{Q}_{1}^{w} \mathbf{Q}_{2}^{w} \ldots \mathbf{Q}_{t}^{w}\right], \mathbf{Q}_{t}^{1, z}=\left[Q_{1}^{z} Q_{2}^{z} \ldots Q_{t}^{z}\right]$.

The conditional and marginal models contain two completely separate sets of latent variables. Thus under some additional assumptions, we can make efficient inferences about the parameters and latent variables in the conditional model, and the marginal model can be neglected due to no information loss. Following Pajor (2011), we have: 
Lemma 1. If

(i) $R_{11}=0, \mathbf{R}_{12}=0, b_{1}=0$,

(ii) $\left(\mathbf{B}_{-1}, \mathbf{R}_{21}{ }^{\prime}, \operatorname{vec}\left(\mathbf{R}_{22}\right)^{\prime}, \boldsymbol{\Theta}_{1}^{q, w}\right)^{\prime}$ and $\boldsymbol{\Theta}_{2}^{q, z}$ are a priori independent, or

(iii) $b_{1}=0, \forall t \in\{1, \ldots, T\} \mathbf{D}_{\mathrm{t}}=0$,

(iv) $\left(\mathbf{B}_{-1}{ }^{\prime}, \mathbf{R}_{21}{ }^{\prime}, \operatorname{vec}\left(\mathbf{R}_{22}\right)^{\prime}, \boldsymbol{\Theta}_{1}^{q, w}\right)^{\prime}$ and $\left(R_{11}, \mathbf{R}_{12}, \boldsymbol{\Theta}_{2}^{q, z}{ }^{\prime}\right)^{\prime}$ are a priori independent, then $\left\{z_{t}\right\}$ is weakly exogenous for $f_{0}\left(\widetilde{\mathbf{Q}}_{T}^{1, w}, \boldsymbol{\Theta}_{1}\right)$.

Hence, assumptions (i) and (ii) in Lemma 1 are sufficient for the Bayesian sequential cut and, consequently, for weak exogeneity of $\left\{z_{t}\right\}$ for $\left(\operatorname{vec}\left(\widetilde{\mathbf{Q}}_{T}^{1, w}\right)^{\prime}, \Theta_{1}{ }^{\prime}\right)^{\prime}$. This means that the inference about the parameters and latent variables of interest, i.e. $\left(\operatorname{vec}\left(\widetilde{\mathbf{Q}}_{T}^{1, w}\right)^{\prime}, \Theta_{1^{\prime}}\right)^{\prime}$ based on the complete process $\left\{\mathbf{Y}_{t}\right\}$ is the same as the one based on the conditional process $\left\{\mathrm{W}_{t} \mid z_{t}\right\}$. Conditions (i) and (ii) in Lemma 1 are sufficient but not necessary for weak exogeneity. In Lemma 1 an alternative set of sufficient conditions that guarantee weak exogeneity of $z_{\mathrm{t}}$ for $\left(\operatorname{vec}\left(\widetilde{\mathbf{Q}}_{T}^{1, w}\right)^{\prime}, \Theta_{1}{ }^{\prime}\right)^{\prime}$ is presented: $\mathbf{D}_{t}=0$ $\left(\mathbf{D}_{t} \neq 0\right.$ implying contemporaneous conditional correlation between $\mathbf{W}_{\mathrm{t}}$ and $\left.z_{\mathrm{t}}\right), t=1, \ldots, T, \quad b_{1}=0$, and the prior independence of $\left(\mathbf{B}_{-1}{ }^{\prime}, \mathbf{R}_{21}{ }^{\prime}, \operatorname{vec}\left(\mathbf{R}_{22}\right)^{\prime}, \boldsymbol{\Theta}_{1}^{q, w \prime}\right)^{\prime}$ and $\left(R_{11}, \mathbf{R}_{12}, \boldsymbol{\Theta}_{2}^{q, z \prime}\right)^{\prime}$.

Once conditions (i) and (ii) in Lemma 1 are satisfied, the conditional model of $\mathrm{W}_{t}$ given $z_{t}$ assumes the form:

$$
\begin{aligned}
{\left[\begin{array}{l}
y_{t, 2} \\
y_{t, 3}
\end{array}\right]-\left[\begin{array}{l}
b_{2} \\
b_{3}
\end{array}\right]=} & {\left[\begin{array}{ll}
r_{22} & r_{23} \\
r_{32} & r_{33}
\end{array}\right]\left(\left[\begin{array}{l}
y_{t-1,2} \\
y_{t-1,3}
\end{array}\right]-\left[\begin{array}{l}
b_{2} \\
b_{3}
\end{array}\right]\right)+} \\
& +\left[\begin{array}{l}
q_{t, 21} \\
q_{t, 31}
\end{array}\right] y_{t, 1}+\left[\begin{array}{l}
r_{21} \\
r_{31}
\end{array}\right] y_{t-1,1}+\left[\begin{array}{l}
\xi_{t, 2} \\
\xi_{t, 3}
\end{array}\right]
\end{aligned}
$$

where $\left\{\left(\xi_{t, 2}, \xi_{t, 3}\right)^{\prime}\right\}$ is the bivariate SV process.

When conditions (iii) and (iv) in Lemma 1 hold, equations (6) and (7) can be written as:

$$
\begin{gathered}
z_{t}=R_{11} z_{t-1}+\mathbf{R}_{12}\left(\mathbf{W}_{t-1}-\mathbf{B}_{-1}\right)+\varepsilon_{t, 1}, \\
\mathbf{W}_{t}-\mathbf{B}_{-1}=\mathbf{R}_{22}\left(\mathbf{W}_{t-1}-\mathbf{B}_{-1}\right)+\mathbf{R}_{21} z_{t-1}+\mathbf{E}_{t, 2},
\end{gathered}
$$

Note that conditions (i) and (ii) in Lemma 1 remain the same for strong exogeneity of $z_{t}$ for $\left(\operatorname{vec}\left(\tilde{\mathbf{Q}}_{T}^{1, w}\right)^{\prime}, \Theta_{1}{ }^{\prime}\right)^{\prime}$. However, conditions (iii) and (iv) are 
not sufficient for strong exogeneity of $z_{t}$ for $\left(\operatorname{vec}\left(\widetilde{\mathbf{Q}}_{T}^{1, w}\right)^{\prime}, \boldsymbol{\Theta}_{1}{ }^{\prime}\right)^{\prime}$. To ensure it, we must assume, in addition, that $\mathbf{R}_{12}=\mathbf{0}$.

The strong exogeneity of $\left\{z_{t}\right\}$ for $\left(\operatorname{vec}\left(\widetilde{\mathbf{Q}}_{T}^{1, w}\right)^{\prime}, \Theta_{1}{ }^{\prime}\right)^{\prime}$ implies that the marginal model suffices (without a loss of information) for predictive inference on $\left\{z_{t}\right\}$ and $\left\{q_{t, 11}\right\}$. On the other hand, the strong exogeneity of $\left\{z_{t}\right\}$ permits to forecast $\left\{\mathrm{W}_{t}\right\}$ from the conditional model, given the forecast of $\left\{z_{t}\right\}$ from the marginal model.

In this paper the conditions for exogeneity need to be tested. Unfortunately, tests of weak or strong exogeneity hypothesis require the joint model to be specified. To test the sufficient conditions (presented in Lemma 1, i-ii) for the strong exogeneity of $\left\{z_{t}\right\}$ for a function of $\left(\operatorname{vec}\left(\widetilde{\mathbf{Q}}_{T}^{1, w}\right.\right.$ )$\left.^{\prime}, \Theta_{1}{ }^{\prime}\right)^{\prime}$ we use the Lindley type test (based on the highest posterior density region, see Box and Tiao, 1973; Osiewalski and Steel, 1993). We set the null and alternative hypotheses as: $\mathrm{H}_{0}: \boldsymbol{\Theta}_{01}=\mathbf{0}$ and $\mathrm{H}_{1}: \boldsymbol{\Theta}_{01} \neq \mathbf{0}$, where $\boldsymbol{\Theta}_{01}$ is the $k \times 1$ vector $\left(\Theta_{01}=\left(b_{1}, r_{11}, r_{12}, r_{13}\right)^{\prime}, k=4\right)$. Then, a posterior, the quadratic form: $F\left(\boldsymbol{\Theta}_{01}\right)=\left[\boldsymbol{\Theta}_{01}-E\left(\boldsymbol{\Theta}_{01} \mid\right)\right]^{\prime} V^{-1}\left(\boldsymbol{\Theta}_{01} \mid \mathbf{Y}\right)\left[\boldsymbol{\Theta}_{01}-E\left(\boldsymbol{\Theta}_{01} \mid \mathbf{Y}\right)\right]$, where $E\left(\boldsymbol{\Theta}_{01} \mid \mathbf{Y}\right)$ and $V\left(\boldsymbol{\Theta}_{01} \mid \mathbf{Y}\right)$ are the vector of posterior means of $\theta_{01}$ and the posterior covariance matrix respectively (in the notation we omit the initial conditions), is approximately $(T \rightarrow \infty) \chi^{2}$ distributed with $k$ degrees of freedom. We assume that if $p\left(F\left(\Theta_{01}\right)>F(\mathbf{0}) \mid \mathbf{Y}\right) \geq 0.01$, the sufficient conditions of the strong exogeneity are not rejected by the data. In the same way, we examine whether $\boldsymbol{\Theta}_{02}=\mathbf{0}$, where $\Theta_{02}=\left(b_{1}, r_{11}, r_{12}, r_{13}, \gamma_{21}, \phi_{21}, \sigma_{21}, \gamma_{31}, \phi_{31}, \sigma_{31}\right)^{\prime}$ (see conditions (iii) and (iv) in Lemma 1).

\section{DATASET AND EMPIRICAL FINDINGS}

Let us consider the daily and weekly 10-year bond yields of the U.S. $\left(y_{t, 1}\right)$, Germany $\left(y_{t, 2}\right)$, and Greece $\left(y_{t, 3}\right)$, over the period of time from July 13, 2006 to January 29, 2016 (downloaded from the website www.stooq.pl). Following Samitas and Tsakalos (2013), the time period covered by the analysis will be divided into three subperiods: (i) the pre-crisis period (from July 13, 2006 to December 31, 2007), (ii) the subprime crisis period (from January 2, 2008 to the end of 2009), (iii) the Greek debt crisis period (from the beginning of 2010 to the end of the time period considered). During the last subperiod the migration and refugee crisis has appeared.

The dataset of the daily (weekly) logarithmic growth rates (expressed in percentage points), consists of 2457 (498) observations (for each series). The 
first observation (in each time series) is used to construct the initial conditions. We analyse both the daily and weekly data to examine whether differences in closing times of markets as well as differences in time zones affect the conclusions regarding the exogeneity of the growth rates of 10year US bond yields. For daily data we start with $T=500$ initial observations (from the period July 13, 2006 - June, 13, 2008, selected ad hoc) and calculate $p=1957$ posterior distributions of parameters and latent variables based on the dataset available at time $T+k$ for each $k=0,1, \ldots, p-1$ (up to $T+p-1=2456$ ). Thus we receive 1957 posterior distributions for the quadratic form $F\left(\theta_{0}\right)$ and posterior characteristics for each parameter and a latent variable. For weekly data we start with $T=98$ initial observations (from the period July 14, 2006 - June, 13, 2008) and calculate $p=399$ posterior distributions of parameters and latent variables based on the data set available at time $T+k$ for each $k=0,1, \ldots, p-1$ (up to $T+p-1=497$ ). Results based on all available data were obtained with the use of the Metropolis and Hastings algorithm within the Gibbs sampler, using $2 \cdot 10^{5}$ iterations after $2 \cdot 10^{4}$ burn-in Gibbs steps (see for details, Gamerman, 1997; Tsay, 2002 and Pajor, 2005, 2007).

Table 1 reports the posterior means and standard deviations (in parentheses) of all the parameters of the VAR-SV model for the daily data. The main posterior characteristics of matrix $\mathbf{R}$ indicate that the daily growth rates of German and Greek 10-year bond yields 'significantly' (and positively) depend on the past daily growth rates of 10-year U.S. bond yields (the posterior standard deviations of $r_{21}$ and $r_{31}$ are relatively small compared to the posterior means). In other words, the daily growth rates of German and Greek 10-year bond yields have been affected by the earlier movements of the U.S. sovereign bond yields. However, the daily growth rates of Greek 10 -year bond yields 'significantly' (and negatively) depend on the past daily growth rates of German 10-year bond yields. On the other hand, the relatively large standard deviation of $r_{13}$ indicates that the U.S. government bond yields were 'insignificantly' affected by the earlier movements of the Greek bond market. The characteristics of the posterior distribution of $r_{12}$ show that the U.S. bond market could have been weakly affected by the German one.

Table 2 reports the posterior means and standard deviations (in parentheses) of all parameters of the VAR-SV model for the weekly data. For this set of data, the main posterior characteristics of matrix $\mathrm{R}$ indicate that the weekly growth rates of 10-year German and Greek bond yields do not 'significantly' depend on the past weekly growth rates of 10-year U.S. 
Table 1

The posterior means and standard deviations (in parentheses) of the parameters of the VAR-SV model (results based on all available daily data)

\begin{tabular}{|c|c|c|c|c|c|c|c|c|c|}
\hline$b_{1}$ & $b_{2}$ & $b_{3}$ & $r_{11}$ & $r_{12}$ & $r_{13}$ & $r_{21}$ & $r_{22}$ & $r_{23}$ & $r_{31}$ \\
\hline $\begin{array}{l}-0.0154 \\
\end{array}$ & 0.0176 & 0.0074 & $\begin{array}{l}-0.0721 \\
\end{array}$ & 0.0433 & $\begin{array}{l}-0.0088 \\
\end{array}$ & 0.0995 & -0.0102 & 0.0085 & 0.0746 \\
\hline$(0.0302)$ & $(0.0253)$ & $(0.0229)$ & $(0.0208)$ & $(0.0128)$ & $(0.014)$ & $(0.0154)$ & $(0.0178)$ & $(0.0142)$ & $(0.0132)$ \\
\hline$r_{32}$ & $r_{33}$ & 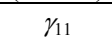 & $\phi_{11}$ & $\sigma_{11}^{2}$ & $\gamma_{22}$ & $\phi_{22}$ & $\sigma_{22}^{2}$ & $\gamma_{33}$ & $\phi_{33}$ \\
\hline-0.1115 & 0.1258 & 1.5022 & 0.9945 & 0.0080 & 2.1591 & 0.9977 & 0.0163 & 0.0882 & 0.9806 \\
\hline$(0.0126)$ & $(0.0173)$ & $(1.2184)$ & $(0.0026)$ & $(0.0022)$ & \begin{tabular}{|l|}
$(3.4782)$ \\
\end{tabular} & $(0.0017)$ & $(0.004)$ & $(0.5484)$ & (0.0049) \\
\hline$\sigma_{33}^{2}$ & $\gamma_{21}$ & $\phi_{21}$ & $\sigma_{21}^{2}$ & $\gamma_{31}$ & $\phi_{31}$ & $\sigma_{31}^{2}$ & $\gamma_{32}$ & $\phi_{32}$ & $\sigma_{32}^{2}$ \\
\hline 0.2228 & 3.5518 & 0.9996 & 0.0006 & -0.2132 & 0.9962 & 0.0005 & -0.4167 & 0.9983 & 0.0007 \\
\hline$(0.0339)$ & $(4.8984)$ & $(0.0005)$ & $(0.0001)$ & $(1.7076)$ & $(0.0024)$ & $(0.0001)$ & $(2.6814)$ & $(0.0014)$ & $(0.0002)$ \\
\hline $\ln q_{11,0}$ & $\ln q_{22,0}$ & $\ln q_{33,0}$ & $q_{21,0}$ & $q_{31,0}$ & $q_{32,0}$ & & & & \\
\hline-0.9253 & -1.3419 & -6.6814 & 0.6471 & 0.6040 & 0.9476 & & & & \\
\hline$(0.3556)$ & $(0.4701)$ & $(1.181)$ & $(0.1355)$ & $(0.1293)$ & $(0.0716)$ & & & & \\
\hline
\end{tabular}

Source: calculated by the authors

Table 2

The posterior means and standard deviations (in parentheses) of the parameters of the VAR-SV model (results based on all available weekly data)

\begin{tabular}{|c|c|c|c|c|c|c|c|c|c|}
\hline$b_{1}$ & $b_{2}$ & $b_{3}$ & $r_{11}$ & $r_{12}$ & $r_{13}$ & $r_{21}$ & $r_{22}$ & $r_{23}$ & $r_{31}$ \\
\hline-0.1488 & 0.0244 & -0.0071 & -0.1235 & -0.0039 & -0.0072 & 0.0054 & $\begin{array}{l}-0.0489 \\
\end{array}$ & 0.0408 & 0.0406 \\
\hline$(0.114)$ & $(0.1143)$ & $(0.1041)$ & $(0.0497)$ & $(0.0273)$ & $(0.0293)$ & $(0.0476)$ & $(0.0414)$ & $(0.0289)$ & $(0.0422)$ \\
\hline$r_{32}$ & $r_{33}$ & $\gamma_{11}$ & $\phi_{11}$ & $\sigma_{11}{ }^{2}$ & $\gamma_{22}$ & $\phi_{22}$ & $\sigma_{22}{ }^{2}$ & $\gamma_{33}$ & $\phi_{33}$ \\
\hline 0.0149 & -0.0412 & 3.1379 & 0.9784 & 0.0213 & 3.7886 & 0.9909 & 0.0795 & 2.7933 & 0.9679 \\
\hline$(0.032)$ & $(0.0389)$ & $(1.4335)$ & $(0.0124)$ & $(0.0098)$ & (3.81) & $(0.0073)$ & $(0.0278)$ & $(1.2479)$ & $(0.0127)$ \\
\hline$\sigma_{33}^{2}$ & $\gamma_{21}$ & $\phi_{21}$ & $\sigma_{21}{ }^{2}$ & $\gamma_{31}$ & $\phi_{31}$ & $\sigma_{31}{ }^{2}$ & $\gamma_{32}$ & $\phi_{32}$ & $\sigma_{32}^{2}$ \\
\hline 0.3016 & 0.7480 & $\begin{array}{l}-0.2668 \\
\end{array}$ & 0.0100 & -2.6439 & 0.9973 & 0.0015 & -0.6397 & 0.9944 & 0.0029 \\
\hline$(0.0967)$ & $(0.0287)$ & $(0.2538)$ & $(0.0052)$ & \begin{tabular}{|l|}
$(4.1063)$ \\
\end{tabular} & $(0.003)$ & $(0.0006)$ & $(3.2335)$ & $(0.0054)$ & $(0.0014)$ \\
\hline $\ln q_{11,0}$ & $\ln q_{22,0}$ & $\ln q_{33,0}$ & $q_{21,0}$ & $q_{31,0}$ & $q_{32,0}$ & & & & \\
\hline 0.7465 & -0.5623 & -10.0913 & 0.2973 & 0.6333 & 0.8970 & & & & \\
\hline$(0.5572)$ & $(0.7217)$ & (3.9209) & (3.7078) & $(0.0757)$ & $(0.1211)$ & & & & \\
\hline
\end{tabular}

Source: calculated by the authors

bond yields. Similarly, the weekly growth rates of 10-year Greek bond yields do not 'significantly' depend on the past weekly growth rates of 10-year German bond yields. These results may arise from the use of more aggregate data, and the aggregation usually implies a loss of information. Finally, we can see that the U.S. bond market has not been affected by the past movements in the German and Greek bond markets.

The lines in Figure 1 illustrate the alteration of the characteristics of the posterior distribution of $r_{i j}$, when the dataset was being increased in one by one observation, from the initial 500 vectors of daily data observations to 2456 , and from the initial 98 vectors of weekly data observations to 497 . The 


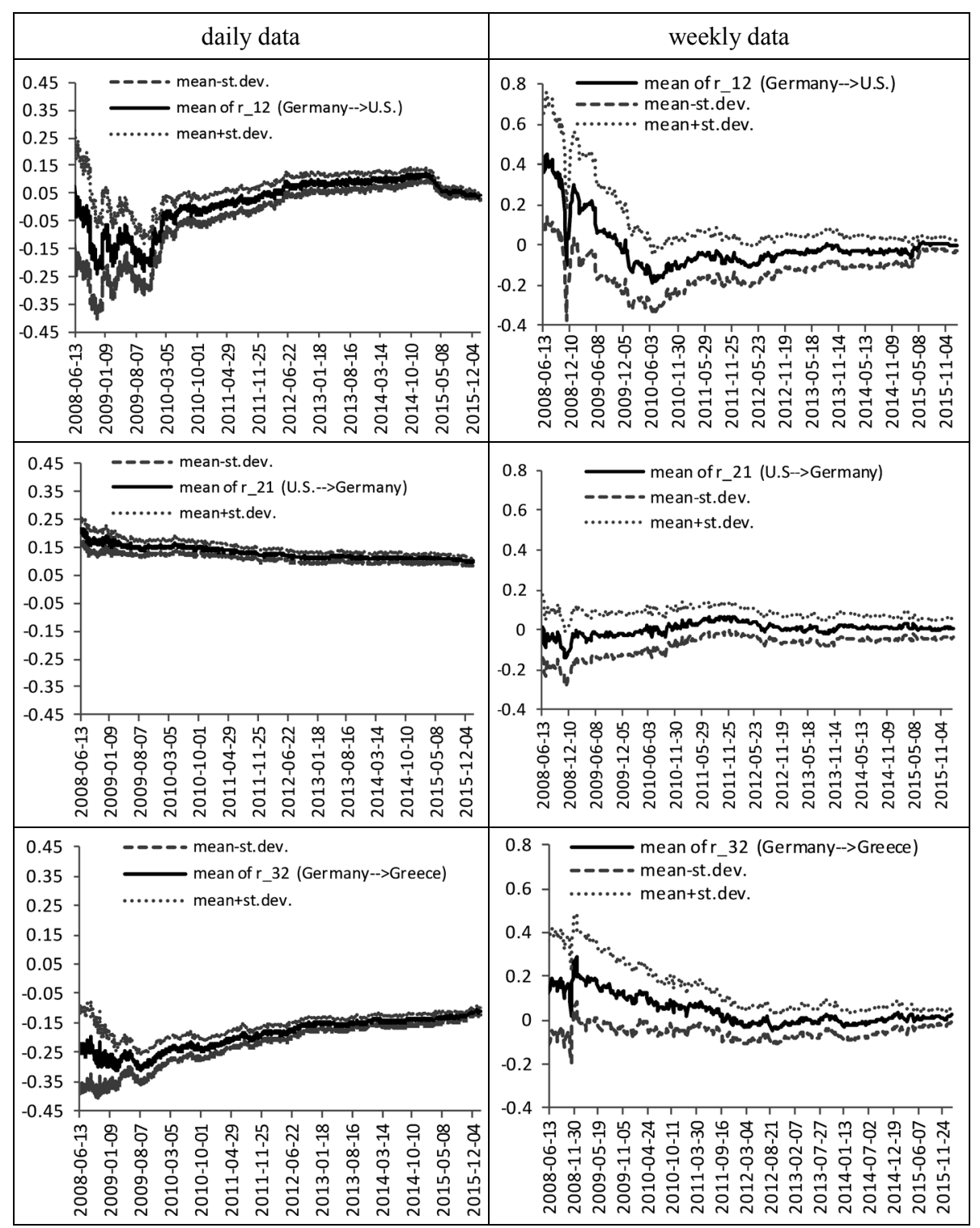

Figure 1. Selected entries of matrix R. The dashed lines represent the posterior means plus (or minus) the standard deviation, and the solid ones - the posterior means. Results based on the data at time $T+k, k=0, \ldots, p-1$

Source: calculated by the authors 
more observations are used, the more concentrated around their means the posterior distributions. This effect can be seen in Figure 1 where we observe the decrease of the posterior standard deviations of $r_{i j}$ (the diminishing distance between the solid and the dashed lines). In the model for daily data the location of the posterior distributions of $r_{12}$ changes significantly from negative values (in the period from November 2008 to January 2010) to positive values (from December 2011 to January 2016), but it is very close to zero. In the middle of November 2008 in particular, the growth rates of 10 -year U.S. Treasury bond yields seem to be negatively affected by the growth rates of 10-year German bonds. The characteristics of the posterior distributions of $r_{21}$ indicate that the impact of the U.S. bond market on the German one decreases slowly. The opposite situation can be observed in the case of the impact of the German bond market on the Greek one (see the plot for $r_{32}$ ). In the model for weekly data the posterior distributions of $r_{12}, r_{21}, r_{23}$ and $r_{32}$ are located around zero, which indicates 'insignificant' dependencies between the German and U.S. bond markets, as well as between the German and Greek ones.

For both datasets the posterior means and standard deviations of $b_{i}(i=1$, 2,3 ) indicate that vector B is 'insignificantly' different from 0 . The formal Bayesian testing (not presented here) would not lead to rejection of the null hypothesis that $b_{i}=0$ for $i=1,2,3$.

It is interesting to analyse the main characteristics of the posterior distributions of the conditional correlation coefficients. The time plots of conditional correlation between the growth rates of the selected countries' sovereign bond yields (for each $t=1,2, \ldots, T+p-1$ ) are shown in Figures 2 and 3 , where the upper line represents the posterior mean plus the standard deviation, and the lower one - the posterior mean minus the standard deviation. It can easily be seen that the conditional correlation coefficients vary over time.

Generally, in the model for daily data the correlation between the U.S. and German bond yields is positive and rather strong; the average posterior mean of $\rho_{12, t}(t=1, \ldots, T+p-1)$ is equal to 0.639 (with an average standard deviation equal to 0.090). Different results were obtained for conditional correlations between the U.S. and Greece as well as between Germany and Greece. From July 2006 to October 2008 all conditional correlations are strongly positive, but from October 2008 (after the collapse of Lehman Brothers) the downward trend related to the posterior mean of $\rho_{13, t}$ and $\rho_{23, t}$ $(t=1, \ldots, T+p-1)$ can be clearly seen. From the beginning of 2010 until November 2015 these correlations are weakly negative. At the end of the analyzed period, the posterior mean of $\rho_{13, T+p-1}$ is equal to -0.12 (with 
posterior standard deviation equal to 0.14 ), while the posterior mean of $\rho_{23, T+p-1}$ is equal to 0.11 (with posterior standard deviation equal to 0.20 ). Among other things, this result is connected with the onset of the sovereign debt crisis in Europe at the end of 2009. In late 2009 a new government in Greece revealed that its predecessors had concealed an enormous budget deficit of $12.7 \%$ of GDP in contrast to the projected $3.7 \%$ of GDP, by the spring of 2010 Greece was unable to borrow on the open markets at an affordable interest rate, and a series of bailout packages was devised by the so-called troika, the EU, the IMF and $\mathrm{ECB}^{5}$.

In the model for weekly data the correlation between the U.S. and German bond markets is also positive and rather strong from the beginning of the period analysed to August 2014. From August 8, 2014 (on this day the United States military began an air campaign in northern Iraq against the socalled Islamic State) the posterior mean of the conditional correlation started to fall and it bottomed out at just over 0.12 on April 24, 2015. From that point on it has risen back to about 0.2. For the conditional correlation between the U.S. and Greek bond markets the downward trend, which starts from October 2008, can be seen. As regards the posterior mean of the conditional correlation between German and Greek bond yields, it also decreased sharply from about 0.9 (in September 2008) to about -0.3 (in September 2011). From September 2008 to February 2015 it was rather flat, ranging from -0.31 to -0.04 . The sudden fall on April 17, 2015 might have resulted from the effects of the ECB's bond-buying programme (the ECB increased its monthly bond purchases of euro-zone debt by one-third). From that point on until December 4, 2015 the posterior mean of the conditional correlation between the German and Greek bond markets started increasing again to the value of 0.5 . In that period of time the European Union was struggling with the migration and refugee crisis.

Additionally, the conditional correlations presented in Figures 2 and 3 provide information about possible contagion effects. If we define contagion between bond markets as a significant increase of the conditional correlation coefficient in a crisis period compared to a pre-crisis period (cf. Pericoli and Sbracia, 2003, Beirne et al., 2013, Philippas and Siriopoulos, 2013, Le and Dickinson, 2014), then no contagion between all the 10-year government bond yield pairs considered can be observed (a formal Bayesian test whether changes in excess correlation are statistically significant has not been presented here), whereas a significant decrease in the conditional correlation

\footnotetext{
${ }^{5}$ https://www.imf.org/external/pubs/cat/longres.aspx?sk=25343 (accessed 28 Apr. 2017).
} 

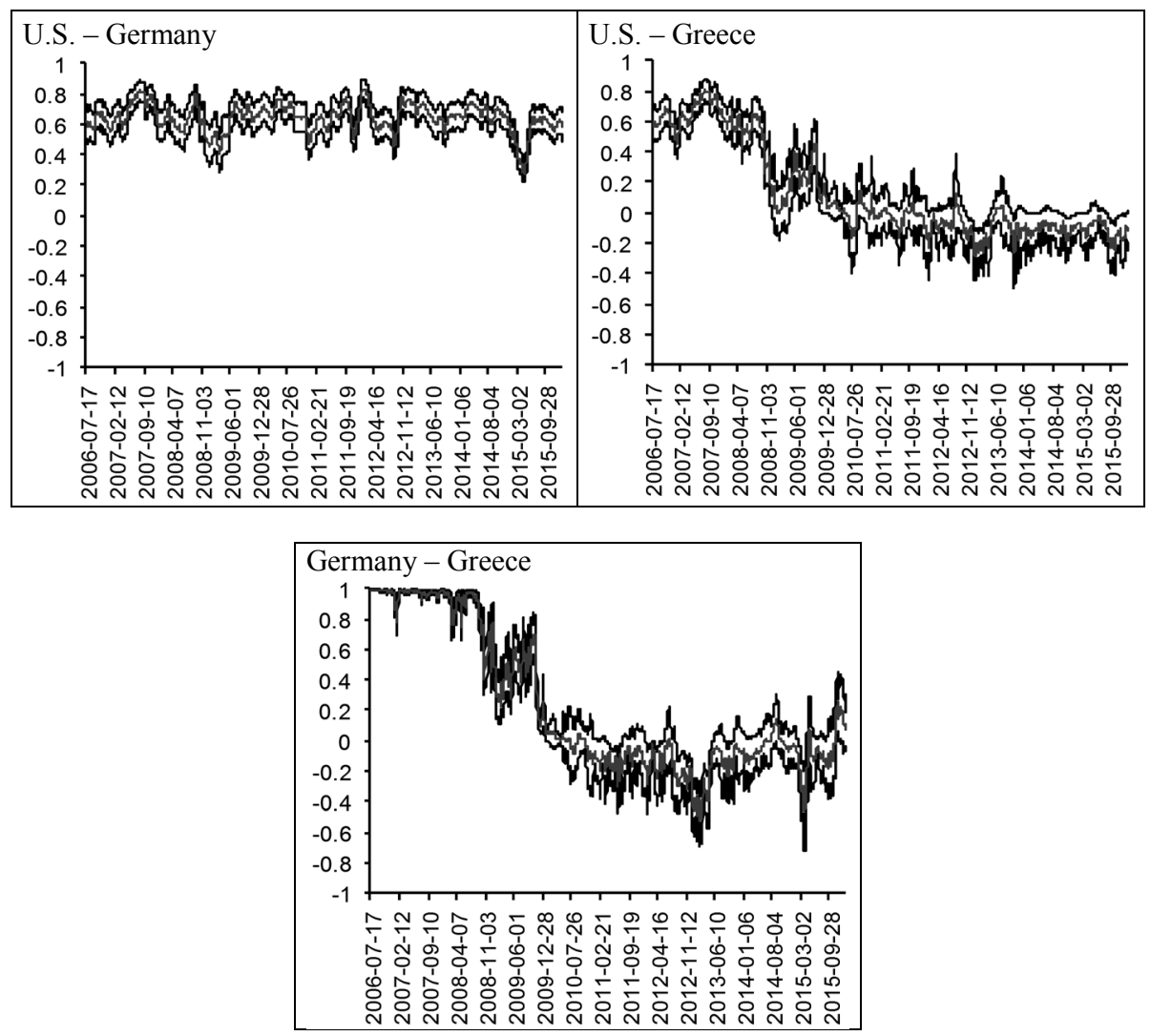

Figure 2. Conditional correlation coefficients between daily growth rates of the 10-year bond yields (posterior mean \pm standard deviation; results based on all data available)

Source: calculated by the authors

coefficient between Germany and Greece as well as between the U.S. and Greece in the period from October 2008 to April 2015 may be explained by the effect known as 'flight to quality' (cf. Kim et al., 2006, Baur and Lucey, 2009, Barrios et al., 2009, Blatt et al., 2015).

Individual volatility of each time series is measured by the conditional standard deviation. The time plots of conditional standard deviations of the daily growth rates are presented in Figure 4, where the upper line represents the posterior mean plus the standard deviation, and the lower one - the posterior mean minus the standard deviation. It can be seen from the graph that volatility of the growth rates of the 10 -year government bonds varies over time. 

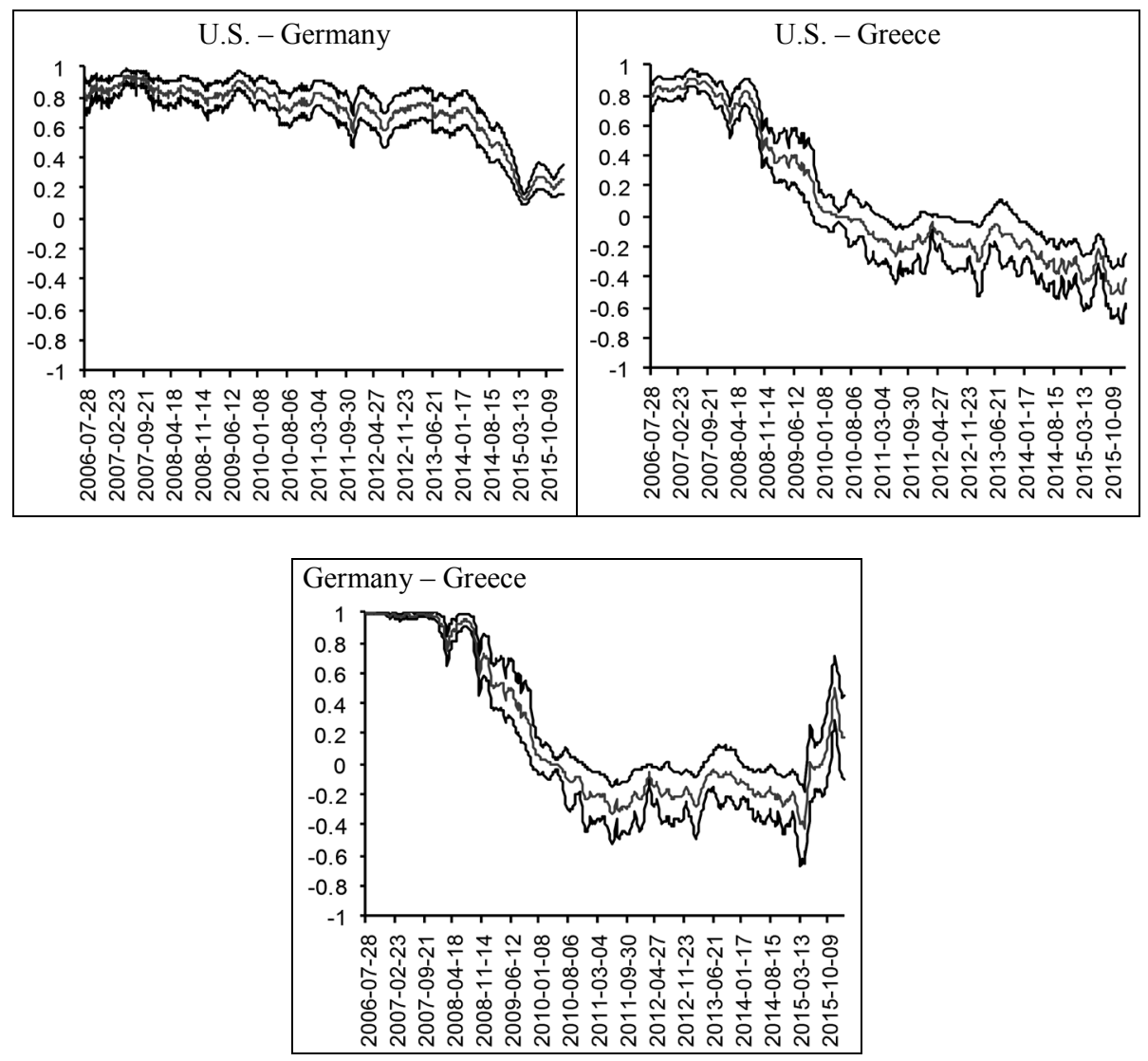

Figure 3. Conditional correlation coefficients between weekly growth rates of the 10-year bond yields (posterior mean \pm standard deviation; results based on all data available)

Source: calculated by the authors

For both datasets the volatility plots for the U.S. bonds are relatively smooth. The dynamics of volatility of the 10-year Greek bond yields is different. The posterior means of the conditional standard deviation are most volatile, with the highest peaks. The first high peaks appeared between April and May 2010 and were connected with the economic situation in Greece (On April 27, 2010 Greece's debt was downgraded to junk level by the rating agencies, in May 2010 a series of general strikes and demonstrations were taking place across Greece), the second one (in March 2012 when Greek 10-year bonds topped 38.5\%) with a sudden decrease of the 10-year 

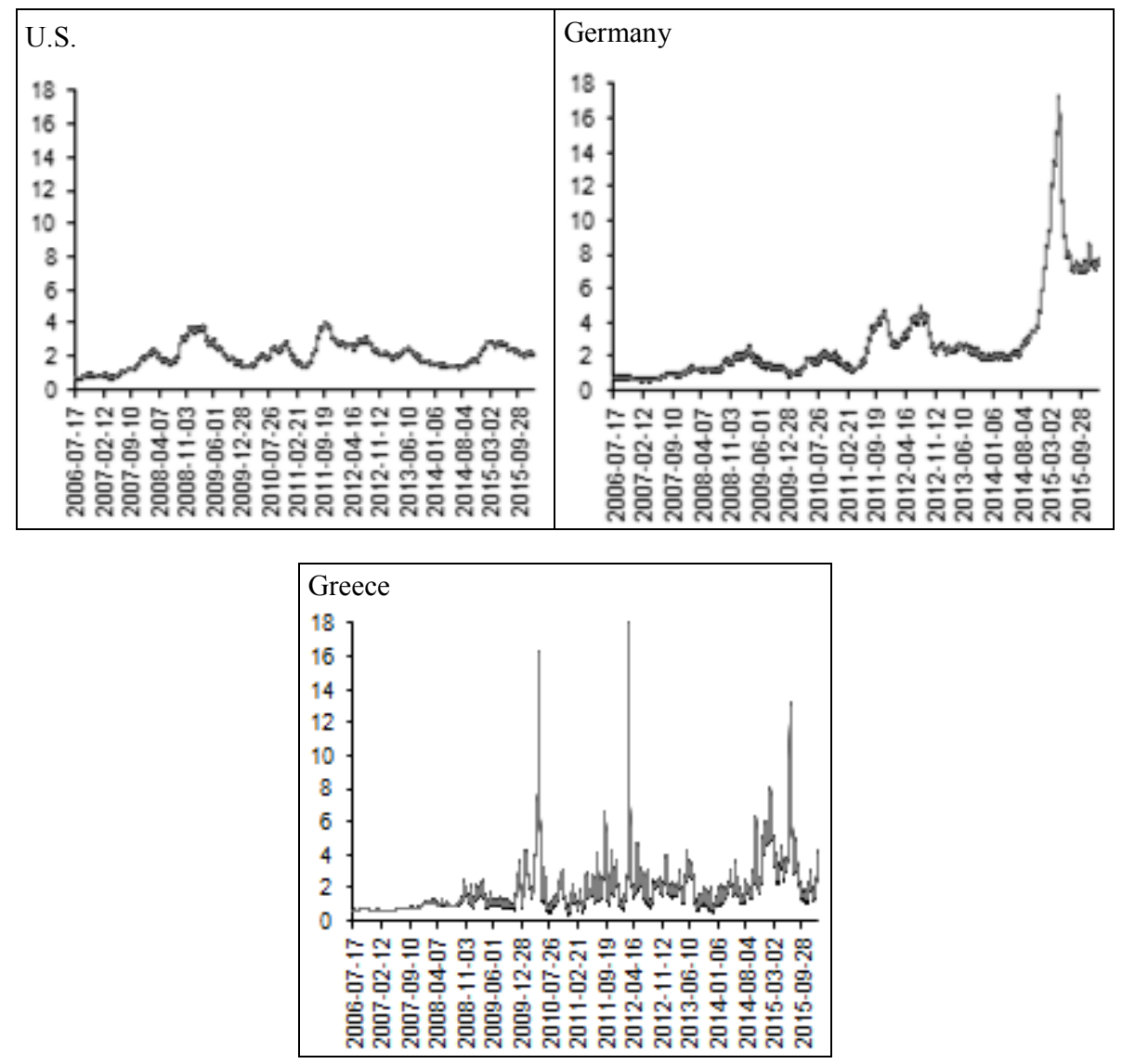

Figure 4. Conditional standard deviations for daily data (posterior mean \pm standard deviation; results based on all data available)

Source: calculated by the authors

Greece bond yields from 36.562 on March 12, 2012 to 19.018 on March 13, 2012 (on May 13, 2012, the credit rating agency Fitch upgraded Greece's long-term foreign and local currency issuer default ratings from 'restricted default' to 'B-' with outlook stable ${ }^{6}$ ). The sudden jumps from June 29 to July 13, 2015 resulted from the decision of the Greek Systemic Stability Council to impose capital controls and to close the banks, and of the Greece's proposition for a third, three-year bailout programme to prevent a

6 news.xinhuanet.com/english/business/2012-03/14/c_122830872.htm (accessed 28 Apr. 2017). 
'Grexit', which triggered protests against carrying on with austerity measures. A significant increase in the posterior mean of conditional standard deviation for the German bonds can be seen in 2015. The volatility of the Germany bonds climbed from 4.16 on December 1, 2014, reached 17.23 on April 22, 2015, and fell to 7.66 on January 29, 2016. Numerous reasons have been suggested as an explanation for the rise in the volatility, for example: 1) the Quantitative Easing (QE) programme of the ECB, 2) the lack of progress in Greek negotiations, 3 ) the migration and refugee crisis.

Suppose that some function of $\left(\operatorname{vec}\left(\widetilde{\boldsymbol{\Theta}}_{T}^{1, w}\right)^{\prime}, \boldsymbol{\Theta}_{1}{ }^{\prime}\right)^{\prime}$ is of interest. As previously mentioned, to test the sufficient conditions (presented in Lemma 1) for the strong exogeneity of the growth rates of the 10-year U.S. bond yields, we use the Lindley type test. For the daily dataset covering the period from July 2006 to December 19, 2012 we obtain $F(\mathbf{0})=13.31$, and $P\left(F\left(\Theta_{01}\right)>F(0) \mid \mathbf{Y}\right) \approx 0.02$. The $98 \%$ highest posterior density interval (HPDI) for $F\left(\Theta_{01}\right)$ does include $F(\mathbf{0})$. In other words, the 98\% HPDI implies that $\Theta_{01}=\mathbf{0}$. Thus the sufficient conditions of the strong exogeneity are not strongly rejected by the dataset.

For daily datasets extended beyond December 19, 2012 the average of $P\left(F\left(\Theta_{01}\right)>F(\mathbf{0}) \mid \mathrm{y}\right)$ is equal to about 0.007 . But for each such dataset the value $F(\mathbf{0})$ lies outside the $95 \%$ HPDI. If the null hypothesis is examined by 95\% HPDI, than the sufficient conditions of the strong exogeneity are rejected.

For all available weekly data $F(0)=9.640$, and $P\left(F\left(\Theta_{01}\right)>F(\mathbf{0}) \mid \mathbf{Y}\right) \approx 0.09$. The 95\% HPDI implies that the sufficient conditions of the strong exogeneity are supported by the data.

In Figure 5 we present the posterior probabilities that $F\left(\Theta_{01}\right)>F(\mathbf{0})$ (and respectively that $\left.F\left(\Theta_{02}\right)>F(\mathbf{0})\right)$ each time $t=T+i-1$ based on updated data set up to time $t=T+i-1$ (for $I=1,2, \ldots, p$ ). The dataset is updated every day (every week for weekly data) from June 13, 2008 to January 29, 2016. Each time when single vector observation was updated into a dataset, we computed these posterior probabilities. It can easily be seen that these probabilities vary with the updating of the dataset. The lowest values are obtained for the daily data completed in the period of time from September 2014 to March $2015\left(P\left(F\left(\Theta_{01}\right)>F(\mathbf{0}) \mid \mathbf{Y}\right) \leq 0.0006\right)$. For datasets including more than 1645 observations (from July 13, 2006 to not sooner than November 7,2011$)$ the value $F(\mathbf{0})$ lies outside the $95 \%$ HPDI. The $95 \%$ HPDI implies that the sufficient conditions of the strong exogeneity of the growth rates of the 10-year U.S. bond yields are rejected by the data. For the weekly data, relatively low (but higher than 0.03 ) values of the posterior 


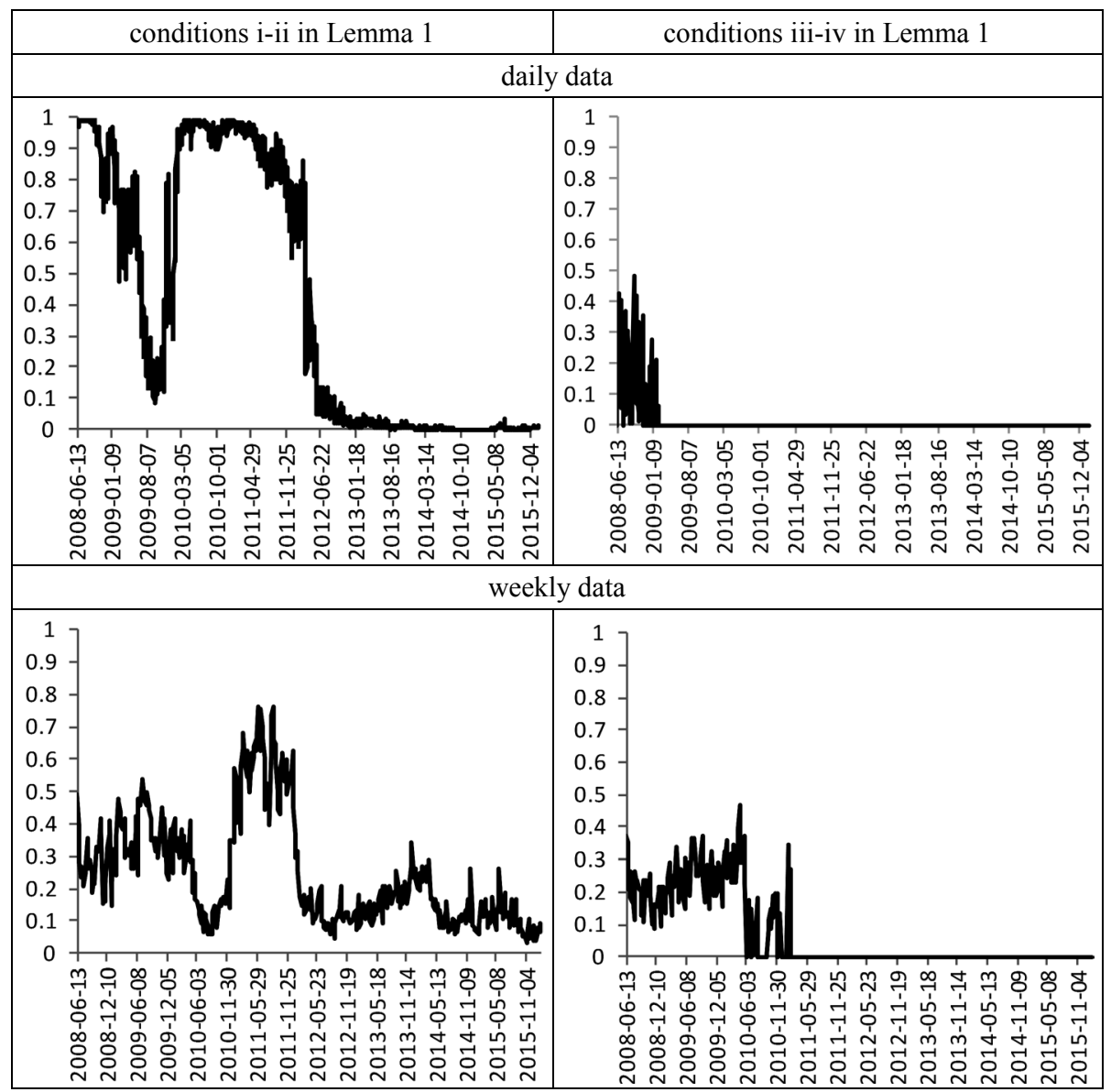

Figure 5. Results for $p\left(F\left(\Theta_{01}\right)>F(0) \mid \mathrm{Y}\right)$ and $p\left(F\left(\Theta_{02}\right)>F(0) \mid \mathrm{Y}\right)$, based on the data at time $T+k, k=0, \ldots, p-1$

Source: calculated by the authors

probability that $F\left(\Theta_{01}\right)>F(\mathbf{0})$ occur between October 2015 and January 2016. If the null hypothesis is examined by the $97 \%$ HPDI, than the hypothesis that $\Theta_{01}=\mathbf{0}$ is not rejected by any datasets.

A different result is obtained when we examine whether $\boldsymbol{\Theta}_{02}=\mathbf{0}$ (see conditions (iii) and (iv) in Lemma 1). The posterior probability that $F\left(\Theta_{02}\right)>F(\mathbf{0})$ from January 2009 (for the daily data) and from December 2010 (for the weekly data) to January 2016 is close to zero, which means that the second set of sufficient conditions of the strong exogeneity of the 
growth rates of the 10-year U.S. bond yields is strongly rejected by the data. For the complete daily data series $F(\mathbf{0})=12590303.8$, that is $P\left(F\left(\Theta_{02}\right)>\right.$ $F(\mathbf{0}) \mid \mathbf{Y}) \approx 0.0000$; and for the weekly data $F(\mathbf{0})=130226.2$, that is $P\left(F\left(\Theta_{02}\right)\right.$ $>F(\mathbf{0}) \mid \mathbf{Y}) \approx 0.0000$. None of the reasonable HPDIs contains $F(\mathbf{0})$.

As a byproduct of the strong exogeneity testing, it has been formally shown that $\mathrm{W}_{t}=\left(y_{t, 2}, y_{t, 3}\right)^{\prime}$ does not cause $z_{t}=y_{t, 1}$, given $Q_{t}^{1, z}$ and $\boldsymbol{\Theta}_{2}$ (see Pajor, 2011). Thus the past of $\mathrm{W}_{\mathrm{t}}$ does not influence the conditional distribution of $z_{t}$ given the past of $z_{\mathrm{t}}, Q_{t}^{1, z}$ and $\boldsymbol{\Theta}_{2}$. Roughly speaking, for weekly data the past values of the growth rates of the 10-year German and Greek bond yields do not influence the growth rates of the 10-year U.S. bonds. Therefore, the forecast of the weekly growth rates of the 10-year U.S. bonds can be constructed from the marginal model only (see equation (6) with $\mathrm{R}_{12}=0$ ) and then forecasts of the weekly growth rates of the 10-year German and Greek bond yields can be obtained from the conditional model (see equation (8)) - without loss of relevant sample information. The result is consistent with our intuition.

\section{CONCLUSIONS}

The examination of the short-term relationships among the U.S., German and Greek bond markets confirmed the asymmetric nature of their connections. The U.S. and German bond markets are more strongly correlated with each other than with Greece. Over the whole period of our analysis, except for a brief interval in November 2008, the status of U.S. Treasuries as a global 'safe haven' remained unchanged. During the financial crisis the weekly growth rates of the 10-year U.S. bond yields were not affected by the past growth rates of the 10-year German and Greek bond yields. Our results indicate also that contagion effects were absent among all the 10-year bond markets considered. However, a 'flight to quality' effect between Germany and Greece, as well as between the U.S. and Greece seems to have occurred in the subprime crisis period and during the Greek debt crisis period respectively.

The econometric research of time-varying interdependence, based on the joint (complete) model for all variables, shows that the weekly growth rates of the 10-year U.S. bond yields can be forecast from the marginal model only, i.e. without taking German and Greek bond yields into consideration (the hypothesis of strong exogeneity has not been rejected by the data), and the weekly growth rates of the 10-year German and Greek bond yields can 
be predicted, without loss of information, from the conditional model, i.e. the predicted values of the 10-year U.S. bond yields obtained from the marginal model may be treated as fixed.

\section{REFERENCES}

Abad, P., Chuliá, H., Gómez-Puig, M., EMU and European Government Bond Market Integration, "Journal of Banking and Finance", 34, pp. 2851-2860, 2010.

Andersson, M., Hansen, L. J., Sebestyén, S., Which News Moves the Euro Area Bond Market?, "German Economic Review", 10, pp. 1-31, 2009.

Barrios, S., Iversen, P., Lewandowska, M., Setzer, R., Determinants of Intra-euro Area Government Bond Spreads during the Financial Crisis, "European Economy - Economic Papers 388", Directorate General Economic and Monetary Affairs (DG ECFIN). European Commission, 2009.

Baur, D. G., Lucey, B. M., Flights and Contagion. An Empirical Analysis of Stock-bond Correlations, "Journal of Financial Stability", 5, pp. 339-352, 2009.

Beirne, J., Caporale, G. M., Schulze-Ghattas, M., Spagnolo, N., Volatility Spillovers and Contagion from Mature to Emerging Stock Markets, "Review of International Economics", 21 (5), pp. 1060-1075, 2013.

Beirne, J., Gieck, J., Interdependence and Contagion in Global Asset Markets, "Review of International Economics", 22 (09), pp. 639-659, 2014.

Blatt, D., Candelon, B., Manner, H., Detecting Contagion in a Multivariate Time Series System: An Application to Sovereign Bond Markets in Europe, "Journal of Banking and Finance" 59, pp. 1-13, 2015.

Box, G. E. P., Tiao, G. C., Bayesian Inference in Statistical Analysis. Addison-Wesley Publishing Company, Massachusetts, 1973.

Campbell, J. Y., Lo, A. W., MacKinlay A. C., The Econometrics of Financial Markets. Princeton University Press, Chichester, 1997.

Chordia, T., Sarkar, A., Subrahmanyam, A., Common Determinants of Bond and Stock Market Liquidity: The Impact of Financial Crises, Monetary Policy, and Mutual Fund Flows. Staff Reports 141, Federal Reserve Bank of New York, 2001.

Clare, A., Lekkos, I., An Analysis of the Relationship Between International Bond Markets, Bank of England's Working Papers 2012/7, available at: http://www.bankofengland.co.uk/ publications/Documents/workingpapers/wp123.pdf.

Christiansen, Ch., Volatility-Spillover Effects in European Bond Markets, "European Financial Management”, 13(5), pp. 923-948, 2007.

Claeys, P., Vašiček, B., Measuring Bilateral Spillover and Testing Contagion on Sovereign Bond Markets in Europe, "Journal of Banking \& Finance" 46, pp. 151-165, 2014.

Da Costa, J. N. C., Cruz, L. V., Leiria, P. S., Government Bond Markets: What Is the Magnitude of Volatility-spillover Effects in the Euro Area?, available at: http://docentes.fe.unl.pt/ jmccosta/JMCCCruzLeiria_04_Volatility-spillovers.pdf, 2004.

Ehrmann, M., Fratzscher, M., Rigobon, R., Stocks, Bonds, Money Markets and Exchange Rates: Measuring International Financial Transmission, "Journal of Applied Econometrics", 26(6), pp. 948-974, 2011. 
Engsted, T., Tanggaard, C., The Comovement of US and German Bond Markets, European Financial Management, "International Review of Financial Analysis”, 16 (2), pp. 172-182, 2007.

Florens, J. P., Mouchart, M., A Note on Noncausality, "Econometrica”, 50 (3), pp. 583-591, 1982.

Florens, J. P., Mouchart, M., Conditioning in Dynamic Models, "Journal of Time Series Analysis", 53(1), pp. 15-35, 1985,

Florens, J. P., Mouchart, M., Rolin, J. M., Elements of Bayesian Statistic. Marcel Dekker, Inc, New York and Basel, 1990.

Gamerman, D., Markov Chain Monte Carlo. Statistic Simulation for Bayesian Inference. Chapman and Hall, London, 1997.

Georgoutsos, D. A., Migiakis, P. M., Benchmark Bonds Interactions under Regime Shifts, "European Financial Management”, 18(3), pp. 389-409, 2012.

International Monetary Fund, Global Financial Stability Report, The Quest for Lasting Stability, April 2012, available at: http://www.imf.org/External/Pubs/FT/GFSR/2012/01/pdf/text.pdf.

Goldberg, L., Leonard, D., What Moves Sovereign Bond Markets? The Effects of Economic News on U.S. and German Yields, "Current Issues in Economics and Finance", 9(9), pp. 1-7, 2003.

Kim, S.-J., Moshirian, F., Wu, E., Evolution of International Stock and Bond Market Integration: Influence of the European Monetary Union, "Journal of Banking and Finance", 30(5), pp. 1507-1534, 2006.

Laopodis, N. T., Government Bond Market Integration within European Union, "International Research Journal of Finance and Economics", 19, pp. 55-76, 2008.

Le, Ch., Dickinson, D., Asset Price Volatility and Financial Contagion: Analysis Using the MS-VAR Framework, "Euroasian Economic Review”, 4, pp. 133-162, 2014.

Lütkepohl, H., New Introduction to Multiple Time Series Analysis. Springer: New York, 2005.

Osiewalski, J., Steel, M. F. J., Una perspectiva bayesiana en selección de modelos [A Bayesian Perspective on Model Selection], "Cuadernos Economicos", 55/3, pp. 327-351, 1993.

Osiewalski, J., Steel, M. F. J., A Bayesian Analysis of Exogeneity in Models Pooling Time-series and Cross-section Data, "Journal of Statistical Planning and Inference", 50, pp. 187-206, 1996.

Pajor, A., Bayesian Analysis of Stochastic Volatility Model and Portfolio Allocation, "Acta Universitatis Lodzensis - Folia Oeconomica", 192, pp. 229-249, 2005.

Pajor, A., VECM-TSV Models for Two Polish Official Exchange Rates [in:] Milo, W., Wdowiński, P. (eds.): Financial Markets: Principles of Modeling, Forecasting and Decision-Making, FindEcon Monograph Series: Advance in Financial Market Analysis 2, pp. 49-66. Łódź University Press, Łódź, 2007.

Pajor, A., A Bayesian Analysis of Exogeneity in Models with Latent Variables, "Central European Journal of Economic Modelling and Econometrics”, 3(2), pp. 49-73, 2011.

Pericoli, M., Sbracia, M., A Primer on Financial Contagion, "Journal of Economic Surveys", 17 (4), pp. 571-608, 2003.

Philippas, D., Siriopoulos, C., Putting the " $C$ " into Crisis: Contagion, Correlations and Copulas on EMU Bond Markets, "Journal of International Financial Markets, Institutions \& Money", 27, pp. 161-176, 2013. 
Samitas, A., Tsakalos, I., How Can a Small Country Affect the European Economy? The Greek Contagion Phenomenon, "Journal of International Financial Markets, Institutions \& Money", 25, pp. 18-32, 2013.

Sosvilla-Rivero, S., Morales-Zumachero, A., “Applied Financial Economics”, 22, (17), pp. 1453$-1464,2012$.

Tsay, R. S., Analysis of Financial Time Series. Financial Econometrics. A Wiley-Interscience Publication, John Wiley \& Sons, INC, New York, 2002.

Received: October 2014, revised: June 2016

Acknowledgements: The initial version of this article came into being within the STAIR PROJECT Studies in Trans-Atlantic International Relations project no. 2008-1747/001-001 CPT-USTRAN realized within the ALTANTIS PROGRAMME - EU-US Cooperation in Higher Education and Training. The final version of this article was partly financed by the funds granted to the Faculty of Finance and Law at Cracow University of Economics, within the framework of the subsidy for the maintenance of research potential. 